\title{
AVALIAÇÃO DA AVALIAÇÃO DA PÓS-GRADUAÇÃO EM EDUCAÇÃO DO BRASIL: QUANTA VERDADE É SUPORTÁVEL?
}

\author{
Amarildo Luiz Trevisan* \\ Catia Piccolo Viero Devechi** \\ EvandRo DotTo Dias***
}

Recebido: 20 dez. 2011

Aprovado: 15 maio 2012

\begin{abstract}
*Doutor em Educação pela Universidade Federal Rio Grande do Sul. Professor do Programa de Pós-Graduação em Educação da Universidade Federal de Santa Maria (UFSM) e pesquisador do CNPq. Santa Maria, RS, Brasil. E-mail: amarildoluiz@terra.com.br / trevisanamarildo@gmail.com

**Doutora em Educação pela Universidade Federal de Santa Catarina (UFSC). Professora do departamento de teoria e fundamentos da Faculdade de Educação da Universidade de Brasília (UnB). Brasília, DF, Brasil. E-mail: devechi@unb.br ; catiaviero@yahoo.com.br

*** Doutorando do PPGE/UFSM. Mestre em Engenharia de Produção: Gerência de Produção, UFSM. Assistente de Planejamento, Controle e Tecnologia do Departamento de Registro e Controle Acadêmico da Universidade Federal de Santa Maria. Santa Maria, RS, Brasil. E-mail: evandrodotto@ufsm.br
\end{abstract}

Resumo: O sistema de avaliação dos programas de pós-graduação em Educação no Brasil vem sofrendo muitos questionamentos desde a sua origem. São muitas controvérsias que apontam para a queda no argumento de que tal sistema se justifica pela busca da excelência. Por trás desse discurso aparentemente convincente, escondem-se os seus efeitos ao longo dos últimos 40 anos: a grande concentração dos programas nas regiões centro-sul do país, tanto em nível de quantidade quanto de qualidade, além da desconsideração com a avaliação dos alunos pelo sistema. Diante disso têm-se levantado diversas dúvidas, entre elas podemos aduzir as preocupações emergentes do âmbito da Filosofia da Educação. A pergunta é se o problema não estaria na epistemologia de base subjetiva (justificação ideal) a que o sistema está ancorado, com pouca referência à verdade do mundo objetivo, tanto da realidade geográfica do país quanto da aprendizagem dos alunos. Para discutir a justificativa do sistema pela busca da excelência e a sua legitimidade prática, a proposta deste artigo se baseia nos aportes da obra Verdade e Justificação, do filósofo alemão Jürgen Habermas.

Palavras-chave: Filosofia da educação avaliação. Pós-graduação em Educação. Justificação. Verdade.

\section{EVALUATION OF THE EVALUATION OF THE POST-GRADUATION \\ IN EDUCATION IN BRAZIL: HOW MUCH TRUTH IS BEARABLE?}

Abstract: The evaluation system of post-graduation programs in education in Brazil has been undergoing many questions since its origin. There are many controversies that point to the fall of the argument that such a system is justified by the pursuit of excellence. Behind this seemingly convincing discourse hide its effects over the past 40 years: a large concentration of the programs in the south-central regions of the country, at both the quantity and quality levels, as well as the disregard for the student assessment by the system. Given this, several questions have been raised, among which we may adduce the concerns emerging from the scope of the Philosophy of Education. The question is whether the problem would not be in the epistemology of the subjective basis (ideal justification) in which the system is anchored, with little reference to the truth of the objective world, both in the geographical reality of the country and the student learning. In order to discuss the justification of the system as the pursuit of excellence and its practical legitimacy, the contributions of this article rely on the work Truth and Justification of the German philosopher Jürgen Habermas.

Key words: Philosophy of Education. Evaluation. Post-graduation in education. Justification. Truth. 
“Quanta verdade suporta, quanta verdade ousa um espírito?

Cada vez mais tornou-se isto para mim a verdadeira medida de valor".

(Nietzsche, Ecce Homo)

\section{ASPECTOS INICIAIS DA DISCUSSÃO}

A avaliação dos programas de pós-graduação pela Coordenação de Aperfeiçoamento de Pessoal de Nível Superior (CAPES), no Brasil, tem sido tema de prolongados debates, desde o seu surgimento em 1976-1977. Trata-se de discussões que buscam analisar os critérios de acompanhamento e avaliação de cursos de pós-graduação, que muitos docentes e discentes têm entendido como recurso para "medir ou controlar" os seus níveis de qualidade. Na área de Educação é expressiva a insatisfação quando os professores são requeridos a atender aos critérios exigidos para alcançarem o conceito de excelência nos programas e, assim, se manterem credenciados. São inúmeras as publicações (MORAES, 2006; CHAUI, 2003; COSTA JUNIOR, 2011; SGUISSARDI, 2009; EVANGELISTA, 2006; NOSELLA, 2010; BIANCHETTI, 2009, entre outros) que anunciam o desagrado da categoria em torno de tais determinações, as quais estariam deixando os professores afrontados e estressados. Em geral as publicações se referem às condições desumanas de trabalho dos docentes, devido ao ambiente competitivo, excesso de horas trabalhadas - cargas horárias dilatadas por aulas, orientações, cursos e palestras - acrescido das condições precárias de funcionamento de muitos programas e da necessidade da busca monitorada por resultados. Além disso, o formato da avaliação tem levado à desarticulação com a graduação, a escola básica e a extensão. Nosella (2010, p. 181) é conclusivo a este respeito, ao dizer: "o fato é que existe e alastra-se cada vez mais, no conjunto dos docentes e discentes, fortes descontentamentos com a forma como se avaliam os programas e suas produções". Não por acaso o Plano Nacional de Pós-Graduação - PNPG (2011-2020) aponta para a necessidade do "aperfeiçoamento da avaliação" (BRASIL, 2010a, p. 15), porém tendo em vista as exigências do novo quadro econômico do país com a perspectiva de se tornar uma das economias mais desenvolvidas do mundo.

Pode-se dizer que existem duas grandes linhas de pensamento sobre esse assunto: uma, que caminha em favor da manutenção da avaliação que vem sendo utilizada e, outra, que a rejeita, por considerá-la excessivamente concentrada na avaliação do aspecto somente quantitativo da produção dos programas. 
A primeira, aposta numa apreciação quantitativa como a melhor maneira de garantir a qualidade, principalmente com a exigência da nova perspectiva econômica de "integração do ensino de pós-graduação com o setor empresarial e a sociedade" (BRASIL, 2010a, p. 17). O argumento se baseia na busca de garantia da excelência acadêmica, pois onde não ocorreu a avaliação, como no caso da pós-graduação lato sensu, não se conseguiu manter garantias mínimas de qualidade. Por outro lado, a segunda é contrária a essa perspectiva, com a justificativa de que o dado quantitativo por si só não garante a qualidade, apenas o controle e o engessamento da política dos programas com poder de delimitar os temas de pesquisa, o número de publicações, a classificação das revistas, etc. Nosella (2010, p. 179) confirma essa visão quando diz que "a pressão produtivista é enorme e estressante. [...] publica-se de forma ansiosa todo tipo de texto em periódicos ou apresenta-se paper em congressos, já chamados no jargão acadêmico de "qualisficado" numa referência ao Qualis". E isso tem gerado uma atormentada corrida atrás de publicações, que muitas vezes recai em práticas superficiais e levianas, como a reprodução da mesma ideia em vários textos, gerando, por vezes, o próprio plágio, a publicação de trabalhos sem base crítica ou científica, etc.

Diante de argumentos pró e contra, o debate tem sido ocupado pela mais antiga das controvérsias contemporâneas: "quantitativo versus qualitativo", que se desdobra em diversas variáveis, como subjetivo ou objetivo, concentrado na formação de centros de excelência ou na perspectiva inclusiva, centrado no professor ou no aluno, estruturalista ou pós-estruturalista, dentre outros, o que tem impedido a possibilidade/necessidade de formatar novos consensos sobre o assunto. Na falta de acordos mínimos, o sistema de avaliação tem dado boas-vindas a coisa nenhuma, ou seja, ele vem se perpetuando e, por isso, a área de Educação trabalhou por três triênios com uma mesma conjunção de fatores, sofrendo apenas pequenas modificações quando se tornou necessário o aprimoramento.

Mas dado que o sistema de avaliação parece não permitir um desenvolvimento equilibrado, minimizando as desigualdades regionais, com foco no crescimento quantitativo e qualitativo da PG Educação no Brasil de maneira descentralizada, perguntamos: até que ponto as diretrizes de avaliação da Capes têm legitimado tais situações frente à necessidade de qualificação dos programas? E ainda, de que forma a rejeição a tal avaliação, que tem se estendido entre os programas de pós-graduação na Educação, pode ser sustentada?

Acreditamos ser este conflito entre a lógica da justificação da "criação de hierarquias de excelência" (PERRENOUD, 1999, p. 9) por um lado, e o realismo 
das práticas de aprendizagens bem sucedidas, por outro, um dos fatores que ocasionam o jogo de forças entre a CAPES e os programas de pós-graduação em Educação. E isso demanda questionar se não há uma atenção exagerada à validade do argumento da excelência acadêmica por si só, deixando de lado o impacto desse discurso na realidade, ou a sua legitimidade nas práticas bem sucedidas diante de um mundo que nos é comum. Afinal, como Habermas (2004, p. 59) afirma: "a verdade que alegamos para uma proposição aqui e agora, no nosso contexto e na nossa linguagem, deve transcender qualquer contexto dado de justificação". E isso gera uma preocupação com o quanto de verdade está contemplado nesses discursos, inclusive na legislação recente (PNPG 20112020) ${ }^{1}$. Ou, então, se não é possível outra via de entendimento dessa questão, na linha do que o próprio Habermas (2004, p. 66-67) acena:

Esse fracasso exige uma série de processos de aprendizado pelos quais as partes conflitantes chegam a descentralizar as suas perspectivas egocêntricas e etnocêntricas de tal modo que possam incluir-se reciprocamente uma a outra na construção conjunta de um mundo mais amplo de relações interpessoais legítimas.

Por isso, neste texto procuraremos apresentar, em um primeiro momento, os propósitos atuais da CAPES em relação à situação da pós-graduação no Brasil. Para tanto, buscaremos identificar a legitimidade da avaliação e suas contribuições concretas para a formação e produção científica da área, a preparação dos profissionais do magistério superior conforme os conceitos avaliativos. E, além disso, procuraremos ver o quanto a preocupação com a efetiva mudança desse quadro está contemplada nesses discursos, inclusive na legislação recente (PNPG 2011-2020). Em seguida, trataremos de algumas críticas que têm sido feitas a tal sistema de avaliação, analisando a simetria regional dos cursos, seu embasamento teórico-pedagógico, mas principalmente a validade do discurso de sua rejeição frente à necessidade de manter o nível de qualidade dos programas. A ideia é identificar o proveito de tais argumentações, no sentido de explicitar a sua efetividade, prevenindo o desgaste com discursos inapropriados ou vazios. Por fim, debateremos a possibilidade da indicação de alguns elementos para melhoria da avaliação dos cursos de pósgraduação, visando contribuir com estratégias ou sugestões para as próximas avaliações e como instrumento facilitador para pesquisadores docentes e discentes, assim como, para uma visão crítica do sistema de avaliação e a

1 A compreensão presente no PNPG é de que a avaliação "deverá sofrer algumas correções de rota, sem dúvida, importantes, ainda que não resultem num novo" (BRASIL, 2010a, p. 22). 
sua "objetividade subjetiva". Para isso, o propósito é buscar inspiração na compreensão pragmática de Habermas (2004, p. 35), em que as interpretações devem refletir "o que a realidade nos ensina em nosso trato ativo com o mundo e o que nos ensinam as objeções que encontramos na troca discursiva". Ou seja, trataremos de repensar a avaliação alicerçada em justificativas acordadas que tenham como base práticas exitosas.

\section{OS PROPÓSITOS ATUAIS DA CAPES EM RELAÇÃO À PÓS-GRADUAÇÃO NO BRASIL}

Atualmente o debate sobre o sistema CAPES de avaliação, realizado na área da Educação, busca ponderar o processo avaliativo e classificatório que tem assombrado a pós-graduação do Brasil. A preocupação com os critérios "objetivos" utilizados para valorar os Programas de Pós-Graduação stricto sensu, frente a uma política de ranqueamento classificatória, determina um sistema que alinha a avaliação diante das múltiplas realidades de um país continental como o Brasil, com diversificadas culturas, etnias, tradições, ethos e costumes.

Segundo Verhine (2008), a educação de pós-graduação no Brasil é o resultado da combinação dos modelos americano e francês, ajustados às circunstâncias particulares. Entretanto, diferente dos EUA onde a determinação do que é, e do que não é "reconhecido", não ocorre dentro do domínio governamental, no Brasil o reconhecimento e a avaliação dos programas de pós-graduação são realizados pelo Ministério da Educação (através da CAPES) e do Conselho Nacional de Educação (CNE). Todos os programas de pós-graduação são classificados em uma escala de 1 a 7 por comitês acadêmicos formalmente constituídos e patrocinados pela CAPES.

Pela âncora legal, o Plano Nacional de Pós-Graduação (PNPG) que indica as políticas e metas para os estudos pós-graduados no país, e a CAPES, que acompanha e avalia a implantação dessas políticas, dentre outros documentos e órgãos, dão a direção e disciplinam os estudos pós-graduados no país (ALVES, 2008). A responsabilidade pela avaliação de Instituições de Ensino Superior (IES) e de cursos de graduação foi concedida ao Instituto Nacional de Estudo e pesquisas Educacionais (INEP). O único componente do sistema que permaneceu fora do domínio do INEP foi o relativo à avaliação da pósgraduação, desde 1976 sob responsabilidade da CAPES (VERHINE, DANTAS; SOARES, 2006).

A Diretoria de Avaliação da CAPES (DAV/CAPES) entende que a avaliação, além de aferir a qualidade dos programas, deve ser um instrumento 
para a sua "melhoria". Por isso, além dos indicadores de produto que tendem a permitir a discriminação, tem-se utilizado na área de indicadores de processo, com a função pedagógica de apresentar o que se espera em termos da organização e do funcionamento dos programas. Embora existam muitas resistências na área de Educação, de forma geral esse procedimento tem sido utilizado pelos programas que planejam as suas ações, balizando-as pelo perfil de "qualidade" definido. Assim, ainda segundo o documento referente ao triênio 2007-2009, destaca-se a necessidade de uma maior organicidade dos programas, a melhoria dos níveis de produção e a maior qualificação dos veículos de publicação. E ainda, é preciso melhorar a classificação dos livros, viabilizar a avaliação qualitativa da produção bibliográfica discente e criar indicadores que permitam avaliar a gestão dos programas.

Já as novas diretrizes do Plano Nacional de Pós-graduação (PNPG) 20112020 apontam para a

exigência de introduzir novos parâmetros e procedimentos nos processos - tanto no sentido de aprimorar o modelo atual, quanto no de corrigir as distorções - havendo aquelas que induzem a um certo conservadorismo dos grupos, junto com a acomodação dos programas; e outros que levam ao produtivismo e à primazia da quantidade (BRASIL, 2010a, p. 22).

O novo PNPG acena com mudanças para essa realidade, mas dado que a estratégia de superação das assimetrias não é repensar a avaliação, mas oferecer apoio aos grupos emergentes para alcançar a excelência junto aos critérios já existentes, esta última também pode se revelar uma orientação pouco eficaz para a superação do problema. Citamos ainda o documento:

a redução no número de mesorregiões sem programas, docentes e bolsas de pós-graduação e, consequentemente, das assimetrias em indicadores de pós-graduação, passa necessariamente pelo apoio e fortalecimento dos grupos emergentes que possuam mérito para tal, sem que com isso se prejudique a consolidação e ampliação dos grupos de excelência, responsáveis diretos pelo atual destaque do Brasil no cenário científico internacional (BRASIL, 2010a, p. 153).

No entanto, acreditamos ser necessário discutir a avaliação não apenas para alcançar o aprimoramento de cada programa de pós-graduação ou dos grupos emergentes. A nossa compreensão é de que, se as discussões não se voltarem à objetividade prática, teremos dificuldade em continuar justificando o ideal de excelência. 


\section{CRÍTICAS AO SISTEMA CAPES DE AVALIAÇÃO}

O Sistema CAPES de avaliação é classificatório e comparativo e, por que não dizer, competitivo. Perguntamos: tal avaliação tem permitido o alcance da "excelência" das práticas dos programas de Pós-Graduação que procuram a melhoria no ranking? O sistema tem conseguido avaliar a formação do aluno frente às necessidades educacionais atuais? Como pensar as práticas de melhoria da pós-graduação tendo em vista que, depois de 35 anos de avaliação, persiste a assimetria no nível de distribuição geográfica qualitativa e quantitativa dos cursos?

É importante perceber um paradoxo que está na origem de contradições importantes da profissão docente: os professores ganharam atualmente maior visibilidade social, em função das necessidades de maior incremento de capital intelectual na produção, isso reforçou o seu prestígio, mas ao mesmo tempo provocou controles estatais e científicos mais vigorosos, o que acabou conduzindo a uma desvalorização da sua autonomia enquanto profissional e a subutilização das suas competências próprias (NÓVOA, 2007). Podemos verificar essa tendência na Educação no Brasil através dos exames da Prova Brasil, ENEM, ENADE, avaliação da CAPES, entre outros.

A avaliação da CAPES procura sintetizar e produtivizar o conhecimento acadêmico e, dentro dele, os programas de pós-graduação e seus docentes e discentes, em uma classificação de publicações científicas padronizadas e tabeladas. A seguir, temos uma explicação de como este modelo é utilizado para a avaliação de cursos de pós-graduação em educação no Brasil, através da curva de Gauss².

Na linha horizontal são colocados os conceitos dos programas 3 ao 7 e, na vertical, os 92 cursos de acordo com a sua distribuição quantitativa. No início aparece os 28 programas 3, seguido dos 42 programas 4, caindo depois para os 13 programas 5 , logo a seguir os 5 programas 6 , e, por último, os 3 programas

2 Johann Carl Friedrich Gauss (1777-1855), matemático, astrônomo e físico alemão, é considerado por muitos o maior matemático de todos os tempos. Foi criador do modelo estatístico da curva de Gauss, utilizado largamente na estatística para representar pontos, dados ou variáveis através de um gráfico em formato de sino. Este comportamento está tão arraigado na cultura da avaliação, que, baseado nos estudos de Arrigues e Zerbato-Poudou, Perrenoud assim o descreve: "dá-se um lote de trabalhos heterogêneos a serem corrigidos por um conjunto de professores; cada um estabelece uma distribuição em forma de sino, uma aproximação da famosa curva de Gauss. Retiram-se então todos os trabalhos situados na parte mediana da distribuição e dão-se os restantes a outros corretores. Poder-se-ia logicamente esperar uma distribuição bimodal. Isso não acontece, cada avaliador recria uma distribuição 'normal'. Obtém-se o mesmo resultado quando se conserva apenas a metade inferior ou superior de um primeiro lote. Os examinadores criam variações que se referem mais à escala e ao princípio da classificação do que às variações significativas entre os conhecimentos ou as competências de uns e outros." (PERRENOUD, 1999, p. 12). 
7. Este modelo é fruto do sistema de "guerra da publicação" e da competição entre os programas incentivado pelo sistema de avaliação CAPES. A partir disso, encaixam-se dentro do viés do ranking os programas de diferentes correntes e diferentes expectativas de formação e discussão. Porém, conforme essas políticas, a ausência de uma cultura de produção científica voltada para a publicação em periódicos traz dificuldades para a subida no ranking de classificação (de 1 a 7), a obtenção de financiamento para a pesquisa, inviabilizando o próprio funcionamento do programa. Ampliam-se assim, para o macro-sistema, os mesmos problemas da avaliação tradicional baseada na "criação de hierarquias de excelência", detectados por Perrenoud, quando informa que: "Ela cria a famosa curva de Gauss, o que permite dar boas e más notas, criando, portanto, uma hierarquia" (1999, p. 15). E isto pode trazer desconforto para aqueles que se dedicam a educação e pensam temas de discussão voltados para a construção social de uma visão crítica no atual modo de vida estetizado pelo capitalismo, consumo e conhecimento-mercadoria.

\section{Gráfico 1 - Os 92 PPGs Educação na curva de Gauss - Triênio 2007 a 2009³}

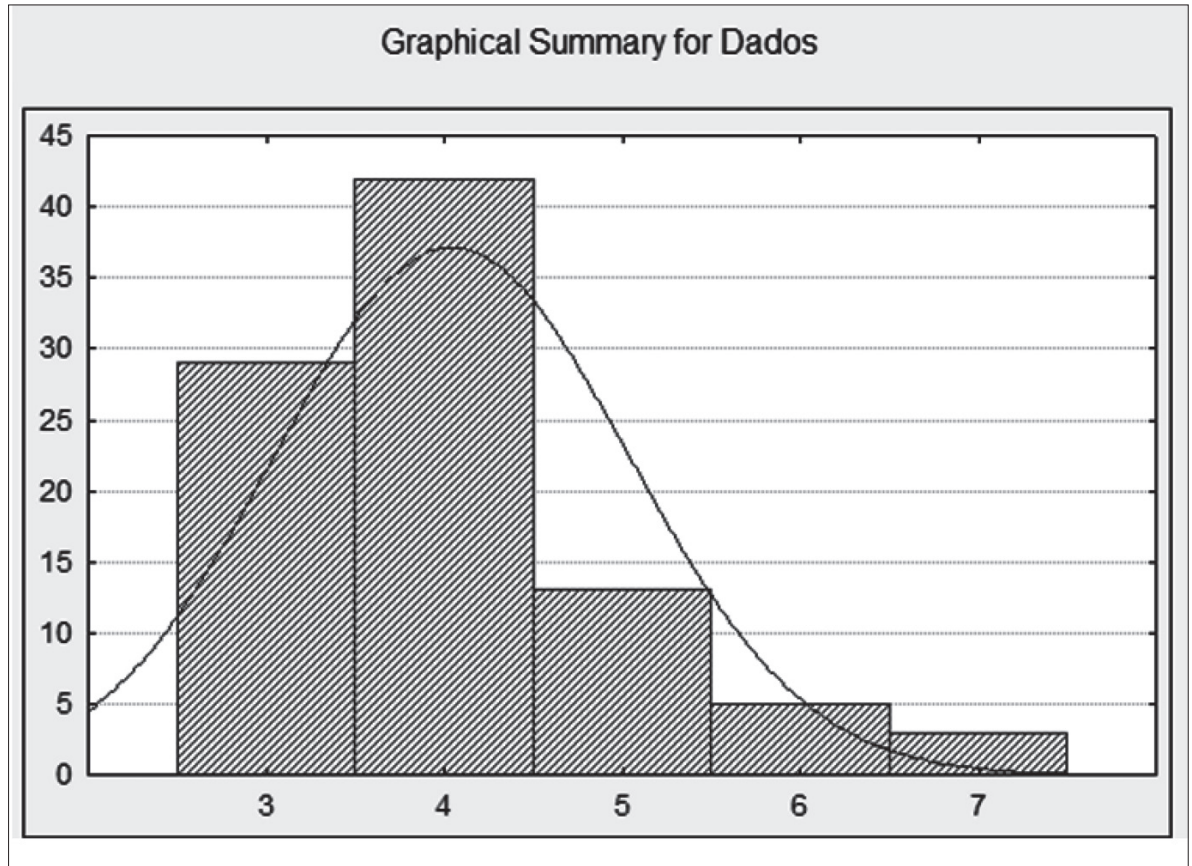

3 Gráfico elaborado pelos autores com base nos dados apresentados nas Planilhas comparativas de Avaliação Trienal 2010 (2007-2009) dos programas de programas de pós-graduação em educação (BRASIL, 2010b). 
Mas por trás desses critérios ditos de "objetividade" da avaliação se escondem outros, que remetem à avaliação de estruturas e não do próprio programa, na medida em que o docente não é avaliado diretamente pelo modelo. Não interessa a qualidade do artigo e, sim, a qualidade do periódico ou da editora avaliada pela própria CAPES, pois o que varia é o estrato de A1 e A2 para internacional, de B1 e B2 para nacional, e assim por diante, podendo chegar ao B5 e depois ao C. Se uma publicação for tramitada e publicada para uma revista A1 receberá o peso 100 e se remetida para uma revista $\mathrm{A} 2,85$, perfazendo uma diferença de 15 pontos entre um estrato e outro, podendo chegar a B5 e receber o peso 10 .

Em relação aos livros, a ordem se inverte, sendo reservado o patamar de L4 e L3 para os que estão mais bem avaliados segundo os critérios de circulação da publicação, e L2 e L1 para os de menor impacto. A avaliação leva em consideração, especialmente para os estratos mais elevados, quesitos de relevância da temática, caráter inovador da contribuição e potencial de impacto, tais como definidos pelo Conselho Técnico Científico (CTC). Além desses aspectos, serão considerados aspectos formais - autoria, editoria, financiamento, reedição, prêmios - que valorizam a obra, embora não sejam obrigatórios. Para fins de classificação, as obras serão subdivididas de acordo com sua natureza em: (a) obra integral; e (b) coletânea e dicionários.

Dentro de uma rápida análise feita aos documentos de outras áreas, já se percebe que a forma de avaliação destas, segundo a Diretoria de Avaliação (DAV), é a mesma, portanto utilizam os mesmos critérios para áreas diferentes, polarizando o sistema avaliativo ao peso atribuído à publicação científica, seja nas áreas da educação, administração, saúde, entre outras.

Se o artigo não for submetido à revista ou editora de maior pontuação ou circulação, poderá não obter a qualidade que realmente deveria receber, pois é contada apenas a avaliação da estrutura. Na verdade, a classificação dependente dessa pretensa objetividade conferida pela estrutura torna-se "subjetiva", pois depende do olhar de avaliadores, não importando as diferentes regiões e diversificados contextos educacionais de onde são os programas dos quais emergem as pesquisas. Ainda em relação aos periódicos e revistas, é possível aos autores das publicações saberem antecipadamente como eles serão classificados. Mas no caso dos livros, como dissemos anteriormente, existe a tabela de classificação, mas a classificação final de cada capítulo ou livro não foi divulgado pela CAPES de forma comparativa entre os programas, o que reforça a impressão de que tal avaliação está muito longe de ser objetiva, pois ao fim e ao cabo ela se torna dependente da subjetividade dos avaliadores. Dentro do que preconiza a avaliação atual, cada vez se torna mais nítido: o que está sendo avaliado pela 
CAPES é a estrutura de publicação e o docente. Na verdade, o discente não está sendo avaliado diretamente pelo sistema CAPES, mas ele recebe em seu currículo (Lattes) o conceito de avaliação do programa.

Além disso, os méritos aferidos pela avaliação estão referendando predominantemente as experiências das regiões centro-sul do país, o que provoca, portanto, as assimetrias regionais. A justificação do sistema de avaliação é a busca da excelência, no entanto o que está sendo conquistado é uma excelência que até aparece na prática, porém de maneira ainda muito limitada, uma vez que somente no último triênio é que 3 cursos da Educação foram qualificados com a nota 7, isto é, com a nota máxima. Na verdade, o crescimento quantitativo - de 1 curso PG sctricto sensu em 1960 para 113 atualmente - não tem sido acompanhado do crescimento qualitativo. Basta perceber que na avaliação do último triênio (2007-2009), menos de 1/3 dos 92 programas avaliados à época, mais exatamente 21 programas, receberam nota acima do conceito 5, ou seja, são considerados programas consolidados, sem contar que apenas 1 curso de PG conseguiu conceito 5 na região Nordeste, fora, portanto, do eixo centro-sul do país. ${ }^{4}$

É certo que para isso o sistema se utiliza de alguns recursos para minimizar as assimetrias regionais como as propostas de MINTER e DINTER, ou seja, os mestrados e doutorados interinstitucionais, em que um programa consolidado assume parceria com instituições de regiões menos favorecidas, como o Norte, Centro-Oeste e Nordeste. Mas no conjunto essas medidas têm sido ainda pouco eficazes, uma vez que, segundo o próprio Plano Nacional de Pós-Graduação (PNPG 2011-2020), enquanto na Alemanha se formam 15,4 doutores para cada cem mil habitantes na faixa etária dos 25 a 64 anos, nos EUA 8,4 e na Austrália 5,9 , no Brasil este índice é de somente 1,4. A previsão do Plano é dobrar esse quociente para 2,8 até 2020 (BRASIL, 2010a, p. 292). Mas isso requer políticas mais ambiciosas de expansão da pós-graduação stricto sensu, semelhante ao que ocorreu na história com o movimento dos bandeirantes, quando se dobrou a vertical do Tratado de Tordesilhas.

Do ponto de vista das teorias da educação, o atual sistema de avaliação favorece uma visão conservadora do conhecimento, estando em descompasso com os avanços das pesquisas realizadas no campo da Filosofia da Educação

4 Observamos esse represamento na historia da educação brasileira, tanto na oferta do ensino fundamental, quanto no ensino médio e, por último, com o aumento da demanda pela formação em cursos de nível superior. É certo que o acesso a esses níveis hoje já está praticamente universalizado, mas isso põe um sério questionamento sobre se tal situação já não está acontecendo pela via de oferta, em larga escala, dos mestrados profissionais e, em breve, dos doutorados profissionais. 
nos últimos tempos ${ }^{5}$, porque baseado na centralização da avaliação quantitativa do professor, sem levar em consideração o mundo da vida dos alunos. Embora esteja protegido por uma noção de excelência da pós-graduação, é prisioneiro de uma epistemologia de base subjetiva, pressuposto do argumento da justificação ideal. Esta epistemologia traz em seu bojo pouca referência às práticas cotidianas - e, portanto, não tem compromissos com valores como a democratização e a humanização da sociedade - dado que ela desconsidera tanto a abrangência da realidade geográfica do país quanto a preocupação com a formação dos alunos.

\section{Desenho 1 - Distribuição dos programas de excelência na educação (conceitos 5, 6 e 7) entre as diferentes regiões do Brasil - Triênio 2007 a $2009^{6}$}

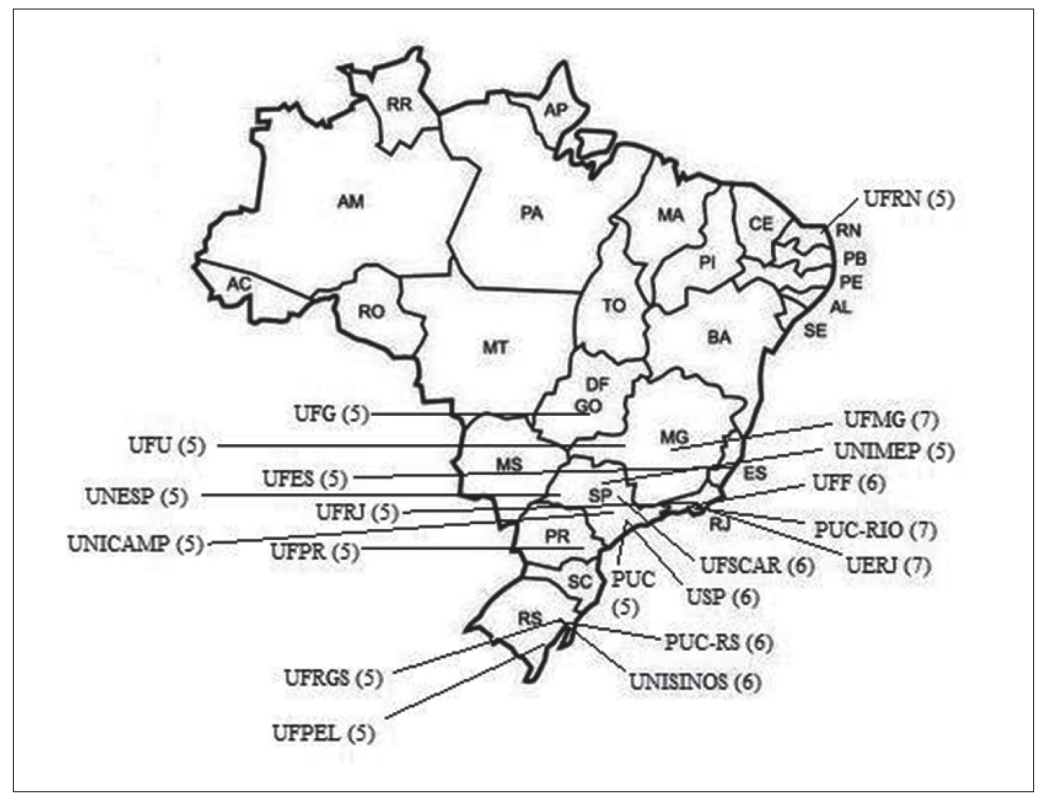

No sentido de fazer uma discussão sobre os discursos idealizados da pósgraduação no Brasil e a necessidade de atender ao seu crescimento quantitativo e qualitativo, bem como aos seus múltiplos contextos, apropriamo-nos da

5 Basta citar aqui a contribuição do escolanovismo, de John Dewey, em que a ligação com a vida define os métodos, conteúdos e práticas de ensino em geral. $\mathrm{O}$ fundamento do agir pedagógico está no compromisso com uma sociedade humanizada e democrática, longe de uma justificativa pautada unicamente na ciência, que se desenvolveu de forma distante da vida cotidiana, e menos ainda guiado pelo trabalho social, vez que este caiu no processo de alienação (VALDEMARIN, 2004; 2010).

6 Mapa organizado pelos autores de acordo com os dados apresentados nas Planilhas comparativas de Avaliação Trienal 2010 (2007-2009) dos programas de programas de pós-graduação em educação (BRASIL, 2010b). 
concepção pragmática de verdade que Jürgen Habermas apresenta na obra Verdade e Justificação. Sua proposta não foi pensada exclusivamente para esse contexto de que estamos falando, mas o transcende, posto que apresente como foco e alcance a dimensão planetária. Portanto, ela está situada para além do que vem sendo adotado na visão empresarial ou mesmo por setores públicos que regulam e normatizam o funcionamento de cursos de pós-graduação, como é o caso da CAPES. Mas sua contribuição é importante na medida em que alerta, por exemplo, não ser prudente permanecermos prisioneiros do discurso (da excelência), pois esse, mesmo que fundamental para pensar os problemas da prática, só pode ser verificado na ação cotidiana junto à resistência do mundo.

\section{O RECONHECIMENTO DA PRÁTICA: A VERDADE PARA ALÉM DAS JUSTIFICAÇÕES}

No estado atual das pesquisas em educação a volta ao objetivismo positivista é impossível, mas também a subjetividade pura já não pode mais ser arguida como um critério de confiabilidade ${ }^{7}$, colocando-se a necessidade de repensar a relação objetivo e subjetivo, verdade e justificação, dentro de outro viés compreensivo. Essa talvez seja uma importante contribuição de Jürgen Habermas para pensar as questões que envolvem a produção do conhecimento, mas também a prática, como é o caso da sistemática de avaliação adotada para os programas de pós-graduação das instituições superiores de ensino.

A partir do confronto com o neopragmatismo de Rorty, Habermas aponta a necessidade de evitar o relativismo da verdade e oferecer às questões empíricas uma resistência realista de um mundo suposto como objetivo. Apesar de se aproximar desse autor na busca pragmática de um mundo mais justo e solidário, Habermas acredita que um caráter de incondicionalidade é necessário no exercício da aprendizagem. Segundo ele, para que sejamos justos com a pluralidade é necessário o reconhecimento de uma objetividade supostamente comum, pois só assim é possível ir além das vantagens práticas contextualistas e avançar na compreensão junto ao outro e com o mundo. Para o autor, a realidade independente preenche "uma exigência funcional de nossos processos de cooperação e entendimento mútuo" (2004, p. 245) que descentraliza os discursos.

7 Ver a este respeito Devechi e Trevisan (2010, p. 148), quando assim se referem sobre as pesquisas qualitativas: "foi por seu intermédio que passamos a considerar elementos não mensurados por meios matemáticos, como a subjetividade, os valores, os contextos, os sentimentos, as diferenças [...]. No entanto, a ampliação do leque de perspectivas de tratamento do objeto educacional não se fez acompanhar de um necessário aprofundamento teórico". 
Na obra Verdade e Justificação, ele propõe ir além do nível argumentativo, tendo em vista que esse, mesmo sendo constituído por um grupo seleto e idealizado, fica sempre no nível hipotético, pois não possui o recurso real de garantia do sucesso prático. Diz Habermas (2004, p. 48):

até mesmo os argumentos que nos convencem aqui e agora da verdade de 'p' podem se revelar falsos em outra situação epistêmica [...] por mais que 'p' seja bem justificado, ele pode se revelar falso - pode ser compreendido como a expressão gramatical de uma falibilidade que experimentamos em nós mesmos no curso de muitas argumentações e que observamos nos outros na retrospectiva histórica sobre cursos de argumentações passadas.

A ideia é descentrar cada vez mais os contextos de justificação, tendo como suposição um mundo objetivo onde possamos nos encontrar "antes mesmo de se entender sobre algo no mundo" (HABERMAS, 2004, p. 240).

Habermas apresenta a suposição desse mundo independente com o objetivo de permitir uma prova para além do discurso. "Pois a argumentação permanece o único meio disponível para se certificar da verdade, porque não há outra maneira de examinar as pretensões de verdade tornadas problemáticas" (HABERMAS, 2004, p. 48-49).

É um mundo entendido não como correspondência da linguagem, mas como possibilidade de oferecer resistência às nossas ações. Diante dele, as nossas práticas dependem de certezas, sem as quais não são possíveis ações confiáveis. Trata-se de verdades não epistemológicas alcançadas pela sustentabilidade na ação, o que significa que "a confiabilidade das expectativas subjetivamente imunes a decepções não suporta nenhuma reserva falibilista consciente durante a ação" (HABERMAS, 2004, p. 49). As práticas cotidianas não podem, assim como acontece no discurso, ser tratadas de forma hipotética, pois se exige confiabilidade naquilo que se considera verdadeiro.

Isso significa que no discurso é possível alcançar apenas justificações, pois é no mundo da ação que nos esbarramos com a resistência do real, portanto, ele é o único espaço de garantia de êxito. Segundo Dutra (2005, p. 140),

é como se o discurso encontrasse um inimigo à altura que o forçasse a sair de sua clausura linguística, ou melhor, forçasse a clausura a se ampliar e a se descentrar, a partir dos desencontros de suas resoluções com o mundo

Mesmo sendo a verdade um conceito sem índex epistêmico, o autor vai dizer que não podemos nos dar o luxo de, no exercício das nossas práticas cotidianas, 
contar apenas com suposições, pois essas, embora confortáveis no discurso, não são fidedignas na ação. Diz o autor:

esse conceito não-epistêmico de verdade que se manifesta no agir apenas operativamente e, portanto, de modo não-temático, confere às pretensões de verdade discursivamente tematizadas um ponto de referência que transcende toda a justificação (HABERMAS, 2004, p. 50).

Segundo o autor, no mundo prático precisamos contar com convicções não problemáticas que nos permitam nele agir sem questionamentos. Diz assim: "no trato prático com um mundo objetivo suposto como idêntico e independente, os atores dependem de certezas da ação" (HABERMAS, 2004, p. 49). Segundo as suas palavras: "a 'verdade' é um conceito que transcende toda a justificação e também não pode ser identificado com o conceito de assertibilidade idealmente justificada. As condições de verdade devem ser preenchidas pela própria realidade" (HABERMAS, 2004, p. 279-280). Assim, tudo o que for justificado num grupo comunicativo deve ser traduzido para a esfera da ação, pois essa é que vai atestar a legitimidade prática do que foi acertado. Para o autor, "o que importa ao mundo da vida é o papel de uma verdade bifronte, que serve de intermediária entre a certeza da ação e a assertibilidade discursivamente justificada" (HABERMAS, 2004, p. 249).

\section{ACERTOS COMUNICATIVOS EM PROL DA EXCELÊNCIA PRÁTICA}

Rossetti e Morales (2007) afirmam que o conhecimento tácito - o conhecimento subjetivo, adquirido pelas pessoas ao longo de sua vida - ainda não aparenta ser tão creditado pelas organizações quanto o explícito, o qual é regrado, metódico e fácil de ser comunicado, pois há dificuldade para geri-lo no âmbito da socialização entre as pessoas. Atualmente a "excelência" (qualidade) dos serviços educacionais constitui-se em algo que provê um diferencial pedagógico estratégico para as ditas "organizações". Por essa razão implica a obtenção de um posicionamento diferenciado para sua efetiva ação e resultado. Tal é o que parece ser o propósito da CAPES na busca por argumentos que possam se colocar como verdadeiros diante da preocupação com a qualidade dos programas de pós-graduação das instituições de diferentes regiões do país.

Habermas tem realizado um esforço para tratar a verdade a partir das exigências da multiplicidade, procurando prevenir injustiças, adequando-a da 
melhor forma possível às necessidades da prática. E é por isso que, diante do movimento teórico da virada linguística, muitas discussões têm sido realizadas em torno do que seria a verdade na multiplicidade discursiva existente. Mesmo sendo corriqueiro entre os autores que o saber precisa considerar a singularidade dos diferentes contextos sócio-históricos,

apenas o entrelaçamento dos dois diferentes papéis pragmáticos que o conceito de verdade bifronte desempenha em contextos de ação e discursos pode explicar por que um justificação bem-sucedida em nosso contexto leva a pensar que uma opinião justificada é verdadeira independente do contexto (HABERMAS, 2004, p. 258-259).

Quando as concepções do mundo da vida são tematizadas, é porque aquilo em que se confiava como verdade era apenas uma verdade pretendida. Nesse momento, entra a tarefa do discurso em que "os participantes adotam uma atitude reflexiva e, à luz de razões pró e contra apresentadas, disputam pela verdade tematizada de enunciados controversos" (HABERMAS, 2004, p. 49). A tarefa do discurso, portanto, é desproblematizar as verdades tematizadas na ação, de modo que elas possam ser devolvidas para o trato ingênuo com o mundo. Fica ao discurso à empreitada argumentativa de reparo das verdades malsucedidas.

Levando isso em consideração, e trazendo essas questões para o campo da avaliação da CAPES, observamos ser necessário supor uma objetividade comum para prevenir contra a predominância do elemento idealista ou subjetivo dos discursos. Se se pensar em termos dos fins emancipatórios da Educação, um desenvolvimento equilibrado, minimizando as desigualdades regionais e com foco no crescimento qualitativo da PG Educação no Brasil, poder-se-iam minimizar os efeitos do círculo perpétuo e recorrente de empobrecimento e desqualificação das forças de trabalho docente e discente.

Percebe-se que o avanço em direção a um discurso descentralizado que encontra a sua excelência prática, passando pelo teste da ação, ainda é uma meta a atingir no sistema atual de avaliação dos programas. Portanto, este é o momento de pensar na avaliação da pós-graduação da educação brasileira que tenha como preocupação e vetor o reconhecimento das práticas bem sucedidas, mas sem que isso signifique utilitarismo. Essa preocupação vai ao encontro do que diz Choo (2003), quando define "organização do conhecimento" como uma tentativa de abandonar uma conceituação de conhecimento como objeto ou coisa que tem que ser conquistada e adotar uma visão mais ampla, como um processo contínuo de construção social e coletiva, incor- 
porado nas tarefas, nos relacionamentos e instrumentos da organização. As justificativas, mesmo que bem argumentadas, devem ser capazes de garantir o consenso e a sua efetividade na ação, que é onde os problemas aparecem. A experiência prática é a forma que temos para identificar os discursos que não servem, sendo, portanto, o espaço de prova necessário ao sucesso das argumentações acordadas.

Com base nos avanços ocorridos nas teorias da educação nos últimos tempos e, no caso da proposta de Habermas, levando o discurso a dar conta dos problemas práticos frente a uma realidade supostamente comum, é possível propor a descentralização da avaliação do âmbito exclusivo de atuação quantitativa do professor para o âmbito de avaliação da formação do aluno. Nesse sentido, os sistemas de avaliação poderiam ser unificados, ao se aproximar da escola básica e da graduação, incorporando a experiência de avaliação da aprendizagem de outros níveis de ensino pelo INEP, como a Prova Brasil, ENEM, ENADE, Avaliação Institucional e de Cursos, etc. Embora sejamos críticos ao caráter redutor que adquiriu o discurso das competências e habilidades na pauta das avaliações do INEP, não podemos sonegar que elas funcionam como uma espécie de âncora diante das necessidades da ação e talvez por isso os seus resultados estejam sendo tão surpreendentes. ${ }^{8}$

\section{CONSIDERAÇÕES FINAIS}

A avaliação dos PPG em Educação deveria ser considerada como um todo, prática e subjetivamente, com o intuito de encontrar uma relação "ótima" para as soluções das questões factuais, não excluindo um elemento pelo outro e, sim, buscando a coexistência (colaboração) entre eles. Afinal, a avaliação das performances na pesquisa em Educação é mais abrangente do que um conjunto de variáveis matemáticas - porquanto é baseada na curva de Gauss, isto é, na criação de hierarquias de excelência; ela envolve também aspectos humanos, políticos, culturais e organizacionais. As anomalias deste modelo são visíveis na medida em que tal sistema favorece: a visão conservadora do conhecimento, uma vez que está assentado numa epistemologia de base subjetiva (justificação ideal), com pouca referência ao «mundo prático» da aprendizagem do aluno; a

8 O Exame Nacional do Ensino Médio - Enem, de 2010, por exemplo, revelou que duas escolas do Piauí - NE, ambas localizadas na capital Teresina, apareceram entre as 10 mais bem colocadas do Brasil. O Instituto Dom Barreto obteve a segunda melhor média e o Educandário Santa Maria Goretti apareceu como sétimo melhor colocado entre todas as escolas do país. O Piauí ainda se destacou entre os cem colégios que mais se saíram bem no exame, tendo cinco instituições nessa lista, superado apenas pelos estados do Rio de Janeiro, Minas Gerais e São Paulo (MORENO; FAJARDO, 2011). 
noção elitista da pós-graduação, posto que os méritos quantitativos e qualitativos aferidos pela avaliação estão referendando predominantemente as experiências das regiões centro-sul do país; o amparo em uma filosofia de base estruturalista, dado que o mérito da produção está alocado de maneira externa ao artigo ou livro, isto é, baseado na estrutura de avaliação do periódico ou da editora; e, a perspectiva tradicional frente às teorias da educação, centralizada na avaliação do professor e com pouca consideração com a formação do aluno - visto como «objeto» e não sujeito da aprendizagem.

Nesse sentido, a avaliação da CAPES poderia promover "olhares de avaliadores" fundamentados numa âncora de preocupação com uma verdade mais ampliada, proporcionando a presença mais acentuada da voz e vez dos avaliados, por exemplo; caso contrário a subjetividade da interpretação pode levar a pretensões de validade falsas. Além disso, poderia repensar as suas bases teóricas e epistemológicas, recuperando os fins da avaliação formativa, não concentrando todo o «peso» político-pedagógico do processo simplesmente na avaliação de estruturas e, principalmente, do docente.

Ao deixar de pesar unicamente sobre os ombros do professor, se equilibraria melhor a avaliação entre os três segmentos do Programa: corpo docente, corpo discente e proposta do programa (condições de funcionamento, impacto social, etc.). Evitar-se-iam também as recorrentes críticas feitas pela academia do sobre-trabalho do docente de pós-graduação, isto é, o estresse e o "adoecimento relacionado com o trabalho" que acontece "em condições intensificadas e extensificadas. Por isso, precarizadas" (COSTA JUNIOR, 2011, p. 13). Talvez esse seja um dos elementos que está faltando no tratamento da busca pela qualidade dos programas de pós-graduação em educação - o acordo entre os discursos que tenha como ponto de partida e de chegada as ações como elas se sucedem no aprendizado com o mundo prático.

A valorização e envolvimento colaborativo de todo o "corpo institucional" coloca-se como indicador de um processo de construção necessário à efetivação prática do discurso de "excelência" pelos programas. Esse impacto (variável quantitativa) pode gerar o indicador que embasaria a variável relacionada à publicação de artigos e livros. A interação entre os discursos e as ações como elas acontecem pode contribuir inclusive para a formação de um entendimento da adequação de conteúdos, discussões e experiências. Esse pode ser um caminho para a efetivação de algumas formas mais concretas e menos subjetivas de avaliação, oferecendo um direcionamento ou redirecionamento de publicações científicas e, consequentemente, a melhoria das pesquisas educacionais dos 
programas. Desse modo, a visão ampliada proporcionada para esses "atores institucionais" serve também de base para permitir a formação de uma troca de conhecimentos capaz de proporcionar a discussão, formação e publicação científica multi e interdisciplinar, geograficamente mais ampla e implicada com aprendizagens mútuas. Se, como diz Habermas (2004), devemos seguir os consensos já estabelecidos na prática e, quando tais situações se tornam problemáticas, migrar os questionamentos para o âmbito discursivo, tal é o interesse que motiva a produção deste artigo.

\section{REFERÊNCIAS}

ALVES, M. V. Formação e trabalho de pesquisadores em educação: um estudo dos processos de institucionalização da pesquisa em IES “emergentes". Tese (Doutorado) - PPGE/CED/UFSC, Florianópolis, 2008.

BIANCHETTI, Lucídio. Os dilemas do coordenador de Programa de PósGraduação: entre o burocrático-administrativo e o acadêmico-pedagógico. In.: BIANCHETTI, Lucídio ; SGUISSARDI, Valdemar (Orgs.). Dilemas da Pós-Graduação: gestão e avaliação. Campinas, SP: Autores Associados, 2009. p. 15-99.

BRASIL. Ministério da Educação. Coordenação de Aperfeiçoamento de Pessoal de Nível Superior - CAPES/MEC. Plano Nacional de Pósgraduação (PNPG) 2011-2020. Brasília, 2010a. v. 1.

BRASIL. Ministério da Educação. Coordenação de Aperfeiçoamento de Pessoal de Nível Superior - CAPES/MEC. Planilhas comparativas de Avaliação Trienal 2010. Área de avaliação: Educação. Brasília, 2010 b. Disponível em: <http://www.capes.gov.br/component/content/article/44avaliacao/4355-planilhas-comparativas-da-avaliacao-trienal-2010 $>$. Acesso em: 14 mar. 2011.

CHAUI, Marilena. A universidade pública sob nova perspectiva. Revista Brasileira de Educação, Campinas, n. 24, set./dez. 2003.

CHOO, Chun Wei. A organização do conhecimento: como as organizações usam a informação para criar significado, construir conhecimento e tomar decisões. São Paulo: SENAC, 2003. 
COSTA JUNIOR, Wercy Rodrigues. Política de avaliação da pós-graduação em suas consequências no trabalho dos professores-pesquisadores. In.: REUNIÃO ANUAL DA ASSOCIAÇÃO NACIONAL DE PÓSGRADUAÇÃO E PESQUISA EM EDUCAÇÃO, 34., 2011, Natal, RN. Anais... Natal: ANPED, 2011. 1 CD-ROM.

DEVECHI, Catia Piccolo Viero; TREVISAN, Amarildo Luiz. Sobre a proximidade do senso comum das pesquisas qualitativas em educação: positividade ou simples decadência? Rev. Bras. Educ., Campinas, v. 15, n. 43, p. 148-161, 2010. Disponível em: < http://www.scielo.br/pdf/rbedu/ v15n43/a10v15n43.pdf>. Acesso em: 14 mar. 2011.

DUTRA, Delamar José Volpato. Razão e consenso em Habermas: a teoria discursiva da verdade, da moral, do direito e da biotecnologia. Florianópolis: Ed. da UFSC, 2005.

EVANGELISTA, Olinda. Publicar ou morrer. In: BIANCHETTI, Lucídio; MACHADO, Ana Maria Netto (Org.). A bússola do escrever. Desafios e estratégias na orientação e escrita de teses e dissertações. 2 ed. São Paulo: Cortez; Florianópolis: Ed. da UFSC, 2006.

HABERMAS, Jürgen. A ética da discussão e a questão da verdade. Trad. Marcelo Brandão Cippola. São Paulo: Martins Fontes, 2004.

Verdade e justificação: ensaios filosóficos. São Paulo: Loyola, 2004.

MORAES, Maria Célia Marcondes de. Avaliação na pós-graduação brasileira: novos paradigmas, antigas controvérsias. In: BIANCHETTI, Lucídio; Machado, Ana Maria Netto (Orgs.). A bússola do escrever:

desafios e estratégias na orientação de teses e dissertações. Florianópolis: Ed. da UFSC; São Paulo: Cortez, 2006.

MORENO, Ana Carolina; FAJARDO, Vanessa. Piauí tem 2 escolas no "top 10” do Enem 2010. In: G1 Vestibular e educação. São Paulo, 12 set. 2011. Disponível em: <http://g1.globo.com/vestibular-e-educacao/noticia/2011/09/ piaui-tem-duas-escolas-no-top-10-do-enem-2010.html>. Acesso em: $14 \mathrm{dez}$. 2011.

NOSELLA, Paolo. A pesquisa em educação: um balanço da produção dos programas de pós-graduação. Revista Brasileira de Educação, Campinas, v. 15, n. 43, p. 177-183, jan-abril. 2010. 
NÓVOA, A. O regresso dos professores. In: CONFERÊNCIA DESENVOLVIMENTO PROFISSIONAL DE PROFESSORES PARA A QUALIDADE E PARA A EQUIDADE DA APRENDIZAGEM AO LONGO DA VIDA. Lisboa, Portugal, 2007. Disponível em: $<$ http://repositorio.ul.pt/ bitstream/10451/687/1/21238_rp_antonio_novoa.pdf >. Acesso em: $14 \mathrm{dez}$. 2011.

PERRENOUD, Philippe. Avaliação: da excelência à regulação das aprendizagens - entre duas lógicas. Porto Alegre: Artmed, 1999.

ROSSETTI, A. ; MORALES, A. B. O papel da tecnologia da informação na gestão do conhecimento. Ciência da Informação, Brasília, v. 36, n. 1, p. 124-135, 2007.

SGUISSARDI, Valdemar. A avaliação defensiva no "Modelo CAPES de avaliação": é possível conciliar avaliação educativa com processos de regulação e controle do Estado? In.: BIANCHETTI, Lucídio; SGUISSARDI, Valdemar (Orgs.). Dilemas da Pós-Graduação: gestão e avaliação. Campinas, SP: Autores Associados, 2009. p. 133-176.

VALDEMARIN, Vera Teresa. Estudando as lições de coisas. Estudos sobre os fundamentos do Método de Ensino Intuitivo. Campinas: Autores Associados, 2004.

. Leitura, impressos e cultura escolar. In.: CASTRO, Cesar Augusto de (Org.). Leitura, impressos e cultural escolar. São Luis: EDUFMA, 2010 .

VERHINE, Robert Evan. Pós-Graduação no Brasil e nos Estados Unidos: uma análise comparativa. Educação, Porto Alegre, v. 31, n. 2, p. 166-172, maio/ago. 2008.

VERHINE, Robert Evan, DANTAS, Lys Maria Vinhaes; SOARES, José Francisco. Do Provão ao ENADE: uma análise comparativa dos exames nacionais utilizados no Ensino Superior Brasileiro. Ensaio: Avaliação de Políticas Públicas em Educação, Rio de Janeiro, v.14, n.52, p. 291-310, jul./ set. 2006. 